Revista Eletrônica de Ciência Administrativa (RECADM) - ISSN 1677-7387

Faculdade Cenecista de Campo Largo - Coordenação do Curso de Administração

v. 1, n. 2, nov./2003 - http://revistas.facecla.com.br/index.php/recadm/

\title{
ADMINISTRAÇÃO RURAL: ELEMENTOS DE ESTUDO NA FAZENDA CÓRREGO DA LIBERDADE NO MUNICÍPIO DE IPIRANGA DE GOIÁS.
}

Mario Lúcio de Avila ${ }^{1}$; Silvia Starling Assad de Avila $^{2}$ \& Cleone José Ferreira ${ }^{3}$

\section{Introdução}

Ter uma chácara ou fazenda para uns é investimento, para outros, lazer. Em qualquer uma dessas condições, a propriedade rural deve ser tratada com muita cautela, do contrário, o investimento corre o risco de ser prejudicado.

A atividade rural é um negócio muito sério. Os custos de produção, a oscilação dos preços, os imprevistos (doenças de rebanho, ou pragas da plantação), os fatores climáticos, a natureza do produto agropecuário (na maioria dos casos perecível), a sazonalidade da produção e a extrema interferência do governo, são fatores que complicam o seu bom andamento.

O homem do campo não pode esperar que as coisas melhorem. É muito complicado ser um produtor rural bem sucedido, a não ser que a fazenda seja encarada como uma verdadeira empresa, onde haja seriedade nos processos administrativos, visando maximizar a lucratividade. resultados.

O agricultor precisa ser um administrador muito competente e dedicado para conseguir bons

O administrador rural deve ter então, subsídios para cuidar da parte administrativa, financeira e econômica de seu estabelecimento; saber dos riscos da exploração da propriedade; planejamento; organização, gestão; controle e direção; volume dos negócios, enfim, informações possíveis que sejam de grande valia ao proprietário rural para que este consiga produtividade e lucro em todo o seu trabalho.

$\mathrm{Na}$ busca por alcançar objetivos consistentes no processo de gerência, o fazendeiro deve ter condições de analisar o desempenho de suas atividades produtivas, levando em consideração os seus objetivos pessoais. De nada adianta acreditarmos que a fazenda precisa ser encarada como empresa, dirigida e controlada dessa mesma forma, se o proprietário encara a mesma como apenas uma atividade de final de semana, onde não importam os investimentos e retornos advindos de seu trabalho.

\section{Objetivos}

O estudo propôs mostrar como aplicar as noções de administração rural, a fim de aumentar a produtividade de uma pequena propriedade rural, levando em consideração as atividades desenvolvidas pelo proprietário atualmente e as possíveis alternativas existentes.

Especificamente, pretende-se:

1) Adaptar o que a propriedade já possui e melhorar sua gestão;

2) Estudar as potencialidades da propriedade;

3) Aplicar técnicas de planejamento, organização, direção e controle, a fim de maximizar os resultados da empresa.

\section{Referencial teórico}

A administração rural é uma ciência é também uma arte, que se iniciou com a análise econômica das culturas e criações, com registros de dados contábeis e técnicos e com a análise de custos de produção. É considerada um ramo da ciência administrativa que não se preocupa apenas em analisar os aspectos inerentes à empresa rural, como também suas inter-relações com o meio ambiente.

Infelizmente, os rendimentos médios da agricultura e da pecuária latino-americana são tão baixos que, por si sós, demonstram em forma categórica e indiscutível que:

a) os erros cometidos pela maioria dos agricultores e/ou dos seus empregados são primários ${ }^{4}$ são provocados principalmente pela falta de conhecimentos elementares; é fácil constatar que a

\footnotetext{
'Zootecnista, Mestre em Administração de Empresas pela Universidade Federal de Lavras, Docente na FACULDADE DE ciências e educação de Rubiataba. Email: hf@ufla.br

${ }^{2}$ Administradora, formada pela Universidade Federal de Lavras, especialista em docência Universitária pela UCG, Docente na Faculdade de Ciências e Educação de Rubiataba. Email: silassad@bol.com.br

${ }^{3}$ Administrador Rural, formado pela FACER - Faculdade de Ciências e Educação de Rubiataba - GO

4 Como por exemplo: não fazer as anotações mínimas que são indispensáveis para melhorar a administração da propriedade, semear fora de época e com espaçamento inadequado, não fazer diversificação de culturas, não fazer rotação com leguminosas ou não inoculá-las; não incorporar a matéria orgânica ao solo, não semear em curvas de nível, queimar a palhada, desperdiçar o esterco dos animais, não fazer análise de solo, não fazer teste de germinação e não regular a plantadeira, atrasar a eliminação das ervas daninhas, não colher no momento oportuno e não regular a colheitadeira; não adotar medidas básicas de prevenção contra as enfermidades e parasitoses dos animais, como por exemplo: vaciná-los ou aplicar parasiticidas, assegurar-lhes o colostro na primeira hora de vida, higienizar as fêmeas e as instalações antes do parto, proteger contra a intempérie e desinfetar o umbigo dos recém nascidos, etc;
} 
Revista Eletrônica de Ciência Administrativa (RECADM) - ISSN 1677-7387

Faculdade Cenecista de Campo Largo - Coordenação do Curso de Administração

v. 1, n. 2, nov./2003 - http://revistas.facecla.com.br/index.php/recadm/

correção dos erros recém descritos não necessariamente requer crédito, insumos e equipamentos de alto custo; e

b) estes erros poderiam ser eliminados se o Estado, diretamente ou em forma delegada, Ihes proporcionasse tão somente a capacitação e as tecnologias que eles necessitam para adotar em forma correta as oito medidas propostas a partir da página 9 deste texto; as quais, diga-se de passagem, não requerem recursos adicionais mas sim necessitam de tecnologias de baixo ou zero custo para que sejam compatíveis com os recursos que eles já possuem.

Se estes baixíssimos rendimentos ${ }^{5}$ demonstram que as ineficiências produtivas ocorrem fundamentalmente por falta de conhecimentos, habilidades e destrezas, o caminho lógico é corrigi-las com tecnologias e capacitação em vez de compensá-las com subsídios e medidas protecionistas: porque enquanto persistirem estes erros, os rendimentos continuarão sendo muito baixo e conseqüentemente os custos unitários de produção serão tão elevados que mesmo que existissem subsídios eles não seriam suficientes para fazer desta agricultura ineficiente uma atividade rentável e competitiva. Este é indiscutivelmente o problema central, o qual devido à sua contundência e evidência ninguém tem o direito de continuar ignorando. (LACKI, 1996)

Com um quadro onde a importância da administração é demonstrada de forma tão clara, é de fundamental importância que os princípios básicos de administração sejam esclarecidos e as funções essenciais da administração precisam ser estudadas, de forma a clarear as diretrizes propostas para 0 estudo.

\section{Planejamento}

"Cada vez mais, os homens de negócios estão compreendendo a importância do planejamento formal e do controle dinâmico das operações de suas empresas... A fim de manter-se no mesmo plano concorrencial, a moderna administração conclui que deve planejar adiantadamente o curso de suas ações, devendo usar técnicas aprimoradas para assegurar o controle e as ações de suas operações...torna-se mais provável a concretização dos objetivos da administração"

WELSCH citado por BARBOSA, (1985)

Uma forma de administrar uma propriedade agrícola é com o planejamento da mesma; a outra e sem planejamento nenhum.

Muitas vezes, uma fazenda aparentemente não tem planejamento; porém, analisando com mais profundidade o andamento dos trabalhos e outros aspectos, percebe-se que a atividade esta planejada - só que empiricamente, "na cabeça do dono ou do administrador". Infelizmente, nestes casos, o dono passa a ser insubstituível na atividade, e se, por algum acaso ele ausentar-se, os negócios podem tropeçar. (BARBOSA, 1985)

O processo de planejamento de uma fazenda, conforme COSTA e GONÇALVES (2002) envolve fornecer respostas para as seguintes questões:

1. O que você quer executar? (metas)

2. O que você tem para trabalhar? (fontes)

3. Com quanto de dívida você consegue conviver? (avaliação da capacidade de correr riscos)

4. O que já foi feito? (análise das performances passadas)

5. O que ainda pode ser feito? (existência de planos alternativos)

6. O que será feito? (apresentar decisões tomadas)

7. Como e quando estas coisas serão feitas? (organizando e direcionando ações)

8. Como o sucesso será garantido? (formas de controlar o empreendimento).

Planejamentos ou orçamentos avançados tomam muito tempo de elaboração por parte do gerente. Ele ou ela tem que estimar os preços das lavouras e animais que cresceram na fazenda. Isto pode ser baseado numa informação histórica; as mudanças esperadas no mercado devem ser consideradas. Depois, o gerente precisa estimar a produtividade das culturas/gado e o custo de produção destes produtos. Estes valores são usados posteriormente para determinar as possibilidades financeiras de eventuais alterações.

Quando se está planejando é interessante estimar como as atividades de lavouras e gado se combinam ou se complementam. Você deve considerar quanto tempo levará para o plano entrar em operação normal, determinando qual será o período de transição. Por fim, as suposições mais importantes

alimentar adequadamente os animais em base aos componentes que poderiam ser autoproduzidos nas sua propriedades, lavar as suas mãos e as tetas das vacas antes da ordenha, etc.

${ }^{5} \mathrm{Na}$ América Latina um hectare de terra produz em média apenas: $1.677 \mathrm{~kg}$ de trigo, $2.207 \mathrm{~kg}$ de milho, $2.343 \mathrm{~kg}$ de sorgo, $782 \mathrm{~kg}$ de feijão (no Brasil apenas $606 \mathrm{~kg}$ ), $9.790 \mathrm{~kg}$ de mandioca, $12.808 \mathrm{~kg}$ de batata inglesa: uma vaca produz em media apenas 1.268 litros de leite ao ano, tem o seu primeiro terneiro aos 42 meses de vida podendo tê-lo antes dos 28 meses e o intervalo entre parições é de 24 meses podendo sê-lo de 12 ou 13 meses; um novilho leva em media 54 meses para atingir o peso de abate, podendo chegar a este peso antes dos 30 meses. 
Revista Eletrônica de Ciência Administrativa (RECADM) - ISSN 1677-7387

Faculdade Cenecista de Campo Largo - Coordenação do Curso de Administração

v. 1, n. 2, nov./2003 - http://revistas.facecla.com.br/index.php/recadm/

precisam ser testadas em uma análise de sensibilidade, para verificar-se o quanto às mudanças nestas estimativas afetam o orçamento.

Geralmente os mais úteis resultados podem ser tirados de um plano completo para fazendas se algumas simples regras estiverem guardadas na cabeça:

1) Orce apenas algumas alternativas que são pertinentes com o problema que se tem em mãos;

2) Estabelecer claramente quais as questões a serem analisadas e respondidas antes de começar a coletar os dados;

3) Uma vez que o plano completo para a fazenda estiver pronto e decidido o que fazer, aja. Indivíduos que planejam, mas falham ao agir, estão gastando tempo de todos os envolvidos, incluindo o mais valioso tempo de todos, o dele mesmo.

Assim, o aperfeiçoamento da atividade rural a exemplo de qualquer outra atividade econômica exige planejamento e controle. Devem ser criadas rotinas de trabalho e normas escritas, de maneira que a organização rural possa substituir seus elementos, sem problemas de interrupção em seus negócios - por que as normas escritas podem ser interpretadas e cumpridas por outras pessoas.

O planejamento é uma moderna técnica de ordenação do sistema econômico, quando se considera uma visão mais ampla do universo. Nesse sentido, podemos entende-lo em nível nacional ou no sentido macro econômico, sendo sua finalidade básica a alocação dos recursos nacionais da maneira mais eficiente possível. (SOUZA et al, 1992)

Segundo MEGGINSON et all (1998) existem algumas vantagens e desvantagens do planejamento. Como vantagens, os autores citam:

1) Ajuda a administração a se adaptar e ajustar as condições mutáveis do ambiente;

2) Ajuda a solidificar os acordos em itens primordiais;

3) Os administradores têm possibilidade de ver o quadro operacional total com mais clareza;

4) Ajuda a definir a responsabilidade com mais precisão;

5) Da mais ordens a operações;

6) Diminui as conjecturas;

7) Economiza tempo, esforço e dinheiro;

8) Ajuda a diminuir erros na tomada de decisão

No entanto, as desvantagens enumeradas pelos autores são:

1) O trabalho necessário para o planejamento pode ser maior que sua contribuição;

2) O planejamento tem a tendência de atrasar a execução

3) Pode impedir a iniciativa e a inovação da administração

4) Às vezes os melhores resultados são obtidos quando um indivíduo avalia a situação e enfrenta cada problema a medida que surge;

5) Poucos planos são seguidos com coerência.

Para MEGGINSON et all (1998) planejar é escolher um curso de ação e decidir com antecedência o que se vai fazer, em que seqüência, quando e como. Está intimamente relacionado a todas as outras funções da administração, principalmente a de controlar.

As empresas que fazem planejamento, mesmo mal, conseguem melhores resultados. Portanto, o planejamento deve ser feito para as empresas terem sucesso.

\section{Organização}

Organizações são grupos de indivíduos com um objetivo comum ligados por um conjunto de relacionamentos de autoridade-responsabilidade; são necessárias sempre que um grupo busca consolidar seus objetivos.

BARBOSA (1985) defende que organização é sinônimo de organismo. Organismo é um conjunto de órgãos, com funções especificas, mas que se inter-relacionam e agem e atuam em conjunto (interagem e interatuam).

Uma organização rural pode ser definida como um conjunto de departamentos integrantes de uma exploração agro-pastoril - organização econômica, ou seja, com objetivo de lucro. Mesmo sendo civil em sua maioria, explorada pelo fazendeiro como pessoa física, deve caminhar para o modelo empresarial.

Para SOUZA et al (1992) a organização da empresa rural pode ser vista sob dois aspectos: organização de pessoal e organização física.

Organização de pessoal se trata de pequenas empresas rurais, podendo ser feita de maneira informal, com o proprietário esclarecendo os funcionários sobre seus cargos e as tarefas que devem executar. O proprietário deve conseguir dos funcionários, também de maneira informal, um comprometimento para a realização de tais tarefas.

Organização física por sua vez refere-se à sua estruturação física, ou seja, àqueles tópicos que se relacionam com a organização dos campos e benfeitorias, máquinas, equipamentos, materiais e etc.

Os departamentos diversos da organização rural são representados no organograma, através dos encarregados dos mesmos. É importante que o proprietário estabeleça a forma dessa organização, o que ajudará a aliviar "a carga das próprias costas" e trabalhar mais tranqüilo. (BARBOSA 1985) 
Revista Eletrônica de Ciência Administrativa (RECADM) - ISSN 1677-7387

Faculdade Cenecista de Campo Largo - Coordenação do Curso de Administração

v. 1, n. 2, nov./2003 - http://revistas.facecla.com.br/index.php/recadm/

Uma boa organização é de extrema importância para o pleno desenvolvimento de uma empresa rural. Quanto mais organizada e estruturada ela estiver, menos problemática será sua direção e mais facilmente serão atingidos os seus objetivos.

\section{Direção e Controle}

A direção é uma função essencial do processo administrativo. Para BARBOSA (1985) de nada vale a elaboração de um bom planejamento e o estabelecimento de uma correta estrutura organizacional se não houver uma direção adequada.

A direção se realiza sobre pessoas e não sobre máquinas, benfeitorias, terras ou animais. É preciso agir sobre os recursos humanos compreendendo suas reações e comportamento.

Segundo o autor, o comportamento das pessoas dentro da empresa é que vai definir o êxito de cada tarefa realizada, e, conseqüentemente a eficiência do empresário na condução dos seus negócios.

Tudo isso, torna-se de fundamental importância para que o empresário rural entenda como é complexo executar ações de direção, uma vez que elas dependem de diferentes situações e das pessoas nelas envolvidas.

O controle que é o processo de se assegurar que os objetivos organizacionais e de administração sejam atingidos, está relacionada intimamente a cada uma das outras funções do administrador (MEGGINSON et all, 1998).

Os sistemas de controle para serem eficazes, devem obedecer a vários critérios:

1) Focalizar os objetivos organizacionais para controlar as atividades adequadas;

2) Agir no tempo certo para a administração poder introduzir uma ação corretiva e ainda atingir os objetivos;

3) Serem eficazes no custo para os benefícios superarem os custos;

4) Dar informações precisas;

5) Serem aceitos pelos que estão envolvidos, ou são afetados, pelo sistema de controle.

Como em qualquer empresa, em uma fazenda, segundo BARBOSA (1985) deve se controlar:

- O patrimônio, ou seja, a propriedade como um todo, como as benfeitorias, as máquinas, ferramentas, os valores a receber, os rebanhos e outros estoques, além, é claro, das dívidas decorrentes das explorações e investimentos na propriedade.

- O resultado, ou seja, as atividades de exploração, ou tudo que gera despesas e receitas na propriedade.

- O rebanho, ou seja, o controle de gado, nos casos de animais leiteiros ou de reprodução, o controle deve ser individual (por cabeça) - controlam-se nascimentos, parições, perdas, produção de leite, etc.

- Além destes itens, há uma enormidade de outros a serem controlados, dependentes do grau de controle a se efetivar na propriedade.

O controle pode ser feito em nível estratégico, onde se procura avaliar o desempenho global da empresa; em nível intermediário, onde cada unidade é avaliada; e em nível operacional, onde se cuida do nível mais baixo da empresa, dando a cada tarefa uma visão de curto prazo (SOUZA et al, 1992).

O controle é vital dentro da empresa, uma vez que permite que erros sejam sanados a tempo, evitando que se comprometam as demais funções da produção. A ele cabe devolver as informações ao planejamento, a fim de que o ciclo da administração tenha continuidade, e verificar se todas as ações estão sendo desempenhadas corretamente. É uma tarefa contínua e fundamental.

\section{Gestão na propriedade rural}

A gerencia da produção agrícola é diferenciada que nos demais setores da economia. O equilibro entre a oferta e a demanda da produção, numa situação de quedas de preços não é retomado simplesmente por uma decisão gerencial. Ocorre que o planejamento da produção normalmente é realizado com meses e até anos de antecedência em relação à entrega dos produtos, e neste período, as condições de mercado podem se modificar, diminuído a precisão entre objetivos traçados e a produção a ser atingida.

Fica difícil conforme citado por NANTES et al (1995) administrar a produção e ajustar a oferta à demanda dos alimentos, se os custos de insumo aumentam, independentemente do aumento dos preços recebidos pelos produtores.

As pesquisas do setor rural caminham no sentido de aumentar a produtividade sem observar a evolução da demanda no mercado, o que invariavelmente termina em excedentes, deprimindo os preços. 0 setor rural deverá se voltar cada vez mais para o consumidor, rompendo a tradição de unicamente produzir.

Torna-se necessário então, que o produtor rural conheça os caminhos que seu produto percorre, sua tendência e evolução dos produtos derivados do processamento. Esta visão, segundo NANTES et al (1995) vista de dentro da porteira de uma fazenda é decisiva, ou seja, é preciso que o produtor rural perceba os impactos da distribuição e comercialização (e também a evolução tecnológica) dos setores relacionados às cadeias de produção das quais seus produtos participam.

A administração é um fator muito importante para o sucesso dos empreendimentos econômicos (MENDONÇA et al, 1995). Ligado à administração estão os empresários que devem estar cientes das quantidades de recursos que devem comprar para produzir um produto. 


\section{Metodologia}

O presente trabalho foi realizado com base em um estudo de caso, que encerra um grande potencial para conhecer e compreender melhor os problemas, relatando o cotidiano em toda a sua riqueza, oferecendo elementos para a melhor compreensão do objeto de estudo com outros objetos.

Para a efetiva coleta e análise de dados, o papel do observador é fundamental, conforme explica LUDKE (1986). O observador deve se fazer aceito e decidir o quanto estará envolvido com as atividades, não tomando partido para nenhum dos lados que a pesquisa poderá apresentar.

A observação para o mesmo autor deve ser controlada e sistemática, com um planejamento cuidadoso do trabalho e uma preparação rigorosa do observador. O observador deve aprender a fazer registros descritivos, deve saber separar detalhes relevantes, aprender a organizar e utilizar métodos valiosos para validar suas observações deve concentrar-se durante a execução de sua observação, o que exige treinamento dos sentidos para se centrar em aspectos que são relevantes.

Além da observação, foram usados dados de fontes secundárias, que permitiram um maior entendimento do contexto em estudo, posicionando a propriedade no âmbito regional e estadual.

\section{Caracterização da Empresa Estudada}

O projeto foi executado numa propriedade rural no município de Ipiranga de Goiás, localizada no córrego da Liberdade.. A propriedade estudada possui cerca de 42 alqueires (203 hectares) e enquadra-se na categoria de média propriedade.

Tradicionalmente, a propriedade atua em atividades pecuária e agrícola, contando com poucas informações sistematizadas e capazes de permitir inferências para análises econômicas ou financeiras.

A propriedade possui solo fértil, tipicamente conhecido por solos de cultura, cortada pelo córrego da Liberdade e possui 18 alqueires (87,12.hectares) plantados com cana de açúcar, 300 cabeça de gado bovino, que representam 300 unidades animais distribuídas em aproximadamene 20 alqueires de pastagem de braquiária (Brachiaria brizantha).

A exploração leiteira da fazenda ocorre com cerca de 50 cabeças de gado cruzado com animais holandeses com produção de leite ao redor de 250 litros diários, perfazendo um média de 5 litros/animal/dia em sistema de produção extensivo, com baixo uso de tecnologia e alimentados a pasto, com suplementação no período de seca utilizando silagem de milho, que fora plantado sob orientação do estagiário, visando ser objeto de análise do presente estudo e que será melhor detalhado mais adiante.

$\mathrm{Na}$ área agrícola, a propriedade tem duas estratégias de busca de retornos econômicos. Por um lado, arrenda parte de suas terras para o cultivo de cana-de-açúcar para a Cooper-Rubi, usina de produção de álcool localizada no município de Rubiataba que assume todas as etapas do processo produtivo da cana na propriedade, trabalhando com remuneração ao produtor capaz de garantir resultados satisfatórios dentre outras alternativas no campo. Além dessa opção, a fazenda desenvolve plantios de culturas anuais, tais como milho, arroz e feijão, de acordo com tendências de mercado e condições climáticas, financeiras e demais variáveis que interferem no processo.

A propriedade possui um sistema de irrigação que garante água a o ano todo para essas culturas e seu uso segue também uma lógica própria que relaciona-se a cultura em questão e condições de mercado.

\section{Resultados}

\section{Caracterização histórica do município e da região do estudo}

Os primeiros agricultores da região de Ipiranga de Goiás foram os caboclos, que iniciaram a exploração das terras roxas e férteis da região. Primeiramente trabalhando com os madeireiros na extração das madeiras - abundantes nas matas regionais - depois desenvolvendo pequenas lavouras de sustentação e de abastecimento dos pequenos povoados que se formavam nas proximidades. No entanto, a tecnologia utilizada e desenvolvida por estes caboclos era rudimentar, provocando uma baixa produtividade e comprometendo a reserva alimentar do povoado em períodos de longas estiagens.

$\mathrm{Na}$ década de 40 , chegaram na região os migrantes gaúchos, cujas colonizações alemã e italiana forneciam-lhes uma tradição agrícola de várias gerações, possibilitando a melhoria do nível tecnológico adotado na agricultura regional. Terras abundantes e férteis não exigiam um aprimoramento técnico para se colher os resultados buscados. A agricultura regional caracterizava-se pelo extrativismo, perfil este que se manteve até a década de 60. Nesta década, chegou à região o serviço de assistência técnica ao agricultor de Ipiranga de Goiás, mudou drasticamente o perfil tecnológico do produtor local.

Os agricultores derrubaram o que restou das matas após a retirada das madeiras economicamente viáveis e queimaram os restos. Muitas vezes, este processo levava vários meses para eliminar totalmente os restos das árvores que ficavam no solo.

Foi um período de alta degradação das férteis terras que compunham o solo agriculturável da cidade de Ipiranga de Goiás, devido ao regime de exploração totalmente extrativista. A agricultura praticada era manual, rudimentar e sem preocupação com a conservação e o manejo do solo. 
Após as queimadas, os agricultores plantavam o solo, abrindo buracos com cavadeiras e jogando as sementes dentro dos mesmos. Os tratos culturais se resumiam às capinas manuais, feitas em torno de 35 dias após a germinação do milho e um achego de terra junto às plantas, operação chamada de amontoa.

A colheita era manual e, na maioria das propriedades, parte da lavoura era cercada e transformada em ceva para suínos, caracterizando-se principalmente como uma agricultura de manutenção.

O milho adquiria uma nova importância, pois sem ele era praticamente inviável uma rotação de culturas com sucesso. Isto fez com que os produtores de boa tecnificação, adquirida no cultivo do binômio soja/trigo, entrassem no cultivo da cultura do milho.

Para estes produtores, a prática agrícola visava, basicamente, a comercialização dos grãos produzidos, fazendo com que a cultura do milho passasse a ser concebida com o mesmo objetivo.

Neste período, surgiam os concursos de produtividade de milho de empresas privadas e de cooperativas. As primeiras (privadas) visavam demonstrar, com a participação dos produtores de nível tecnológico mais elevado, o potencial produtivo de seus híbridos; as segundas (cooperativas) visavam desenvolver o nível tecnológico de seus cooperados.

A produtividade no segmento de maior tecnologia crescia rapidamente, saindo de produções máximas de 4 toneladas por hectares, no começo da década, para 9 toneladas, em algumas áreas, no final dos anos 80 .

Iniciava-se o sistema de "silagem de grão úmido" (o milho é colhido e ensilado quando ainda está com $35 \%$ de umidade no grão, para posteriormente ser utilizado na avicultura e na suinocultura) e o plantio da "safrinha" de milho (plantio no período de janeiro a março, após a colheita da lavoura, normalmente, de soja).

Nos anos 90, era o período da consolidação da agricultura tecnificada na cidade de Ipiranga de Goiás. Os filhos de produtores com curso superior começaram a assumir as propriedades. As tecnologias passaram a ser discutidas/debatidas em seminários específicos, buscando um maior retorno das partes envolvidas (produtor e fornecedor). Os seminários/ encontros e cursos sobre a cultura do milho eram organizados por cooperativas, associações de engenheiros agrônomos e empresas privadas.

O milho deixa de ser, definitivamente, uma cultura de "fundo de quintal" para ser parte integrante do "pacote" produtivo da maior parte das propriedades agrícolas goianas.

Os concursos de produtividade de milho aumentaram em número e importância. A produtividade continuava sendo a principal característica na definição da variedade a ser plantada. No entanto, ao seu lado, aparece, com igual importância, a resistência às doenças e a estabilidade dos materiais, entendendose por estabilidade a capacidade de resistência que uma variedade de milho tem às condições adversas do clima, mantendo-se um nível de produtividade satisfatório (5.000 kg. /ha.).

Algumas propriedades rurais começam a utilizar, a partir da metade da década, computadores pessoais, para auxiliarem nos controles dos custos, além de passarem a acompanhar as previsões climáticas e os preços das diversas culturas através da Internet.

As áreas tecnificadas alcançam um nível de produtividade médio em torno de 8 toneladas por hectare, havendo ainda um crescimento no plantio de milho na "safrinha". A partir de 1996, começaram a serem vinculadas notícias desencontradas sobre o uso da biotecnologia (organismos geneticamente modificados) na agricultura, principalmente na cultura do milho. Algumas versavam sobre o benefício deste tipo de variedade, e outras enfocavam o malefício que este poderia causar ao ser humano e ao meioambiente.

\section{Análises e considerações acerca da propriedade}

A propriedade em estudo oferece um quadro que permitem algumas considerações, dadas principalmente por sua estrutura familiar de gestão e os métodos tradicionais consagrados de administração.

É interessante notar que, o proprietário é extremamente consciente da importância das ações administrativas de planejamento, direção, controle e organização, no entanto, devido principalmente ao grau de dificuldade por ele mesmo atribuído a essas ações, raramente ele executa formalmente alguma delas.

Além disso, dado o distanciamento que a propriedade tem em relação aos órgãos de extensão rural, pesquisa e desenvolvimento, as técnicas conhecidas pelo proprietário chegam geralmente, maquiadas por programas de televisão ou por notícias que correm na boca dos vizinhos e amigos.

Raramente o proprietário recebe a visita de um técnico não comprometido em vender algum produto, o que aumenta sua desconfiança em relação aos propósitos das visitas e em outras ocasiões, nada do que já existe e encontra em andamento parece atender aos anseios dos técnicos. A seguinte fala retrata a questão

Os técnicos que vem aqui só querem vender algum produto. As vezes aparece o técnico da Agência Rural ou outro que é para falar da vacinação do gado, mas só isso. Outro dia teve um que falou que voltava, mais até hoje nada... (Fala do proprietário) 
É importante frisar que o proprietário com suas dificuldades e ausência quase que total de assistência técnica, faz da propriedade seu principal sustento, mantendo sua casa, dois filhos em idade escolar e consegue ainda reverter em benefícios para estes boa parte do retorno obtido com a fazenda.

\section{Administração e pecuária de leite}

$\mathrm{Na}$ fazenda em estudo, a pecuária de leite é a atividade tipicamente familiar, onde a contabilidade realizada é feita baseada em relação de troca, com poucos subsídios econômicos para análise. Computa-se de maneira geral, os ganhos acessórios advindos de outros processos que no final das contas podem significar a diferença entre ganhar ou perder na atividade.

A pecuária de leite tradicionalmente tem enfrentado diversos problemas, onde as principais queixas relacionam-se ao preço recebido pelo produtor, a falta de incentivo governamental e coisas afins. Deve-se entender que para muitos produtores, o preço do leite realmente constitui-se em fator determinante à sua sobrevivência na atividade, no entanto, o pequeno produtor, tem em suas estratégias, opções importantes para a sustentação da atividade.

Em primeiro lugar, devemos levar em consideração que o leite é geralmente encarado como produto de sustento da família, servindo em primeiro lugar a manutenção dos membros da casa e daqueles que trabalham na fazenda;

Segundo, quando da produção de produtos originados do leite, tais como manteiga, queijos, iogurtes, doces, etc, a fazenda pode até obter retornos satisfatórios, inclusive sendo esse o argumento de muitas agências de desenvolvimento no sentido de melhorar a renda no campo para os produtores de leite - a expansão horizontal da atividade, através da agroindústria caseira.

Terceiro. Normalmente a atividade leite é deficitária quando analisada isolada, ou seja, apenas como produtora de leite. No entanto a atividade como um todo envolve também a produção de bezerros e bezerras para comercialização e o descarte de vacas que devem ser computados para a analise total do negócio. Neste ponto, é importante salientar que nem sempre quem segura as pontas é a venda de animais. O que é certo é que a venda de animais é mais um item que contribui para as receitas da fazenda. Nada se pode afirmar neste sentido se não houver uma análise criteriosa dos custos envolvidos na produção de leite e na produção de animais jovens (fêmeas e machos).

Sob esse ponto de vista, pode se observar que a fazenda em estudo tem nas estratégias de alternativas de produção e utilização de recursos um elemento importante. Para efeito foi realizado um plantio de milho e nas palavras do produtor, a estratégia é a seguinte:

"Na área agrícola será feita uma plantação de milho que será plantado semanalmente, com o objetivo de vende-lo para as pamonharias, feiras, etc., e com isto tirar os custos da plantação. E no período da seca será utilizada uma irrigação, irrigação está já existente na propriedade, para a plantação deste milho.

Já foi feita uma pesquisa de mercado para saber onde vender este milho, como especificado anteriormente.

E com a palha do milho será aproveitada para a alimentação das vacas leiteiras, e com isto diminuir os custos para o proprietário, pois a palha já vai ter um custo quase nulo. E para melhorar a produção leiteira pretendo com este volumoso dar uma suplementação conforme orientação de especialista no assunto." (Fala do proprietário)

Evidencia-se a importância de buscar racionalizar a produção de leite e a agricultura da fazenda. Os agricultores mais realistas já estão se dando conta que para ter rentabilidade e competitividade é indispensável que eles cumpram simultaneamente os seguintes pré requisitos:

- Melhorar a qualidade dos produtos colhidos;

- Reduzir ao mínimo os custos unitários de produção (através da diminuição do custo dos fatores e do incremento dos rendimentos por unidade de terra e de animal);

- Aumentar ao máximo a receita obtida na venda dos seus excedentes (através da diminuição das perdas durante e depois da colheita, da incorporação de valor agregado e da eliminação daqueles elos da cadeia de intermediação que são reconhecidamente desnecessários).

Estas são as principais tarefas que o produtor rural deve aprender e para o pequeno produtor é fundamental esse entendimento. Não deve ser visto, no entanto como uma receita. A estratégia de sobrevivência do pequeno produtor passa por esses pontos, incluindo ai a diversificação produtiva como forte elemento na sobrevivência na fazenda.

\section{Administração Rural na prática}

Algumas ações executadas pela fazenda merecem destaque. Nota-se que a associação de práticas culturais corretas, controle, manejo adequado podem garantir alguns bons frutos na atividade.

Boa parte dos ganhos em produtividade, tanto na produção de leite como na área agrícola da fazenda é seguramente proveniente do manejo da fertilidade do solo, tanto aquele realizado pela 
arrendatária de parte da área da fazenda como pelo proprietário. Este manejo é dividido em práticas corretivas e práticas de adubação.

Depois das práticas corretivas adota-se a prática da adubação anual, que pode ser do tipo química ou orgânica, ou a associação de ambos. Na pastagem já formada, o calcário e os fertilizantes são todos aplicados a lanço sem incorporação.

Depois de feita a correção do solo; na fase de adubação, são aplicados de forma parcelada os nutrientes $\mathrm{N}, \mathrm{P}, \mathrm{K}$.

A fertilidade do solo e sua manutenção são fundamentais para a sustentação da atividade agrícola e pecuária, uma vez que o solo consiste no suporte dos processos produtivos em questão. De nada adiantaria um complexo gerencial que deixasse de lado o item básico de apoio aos processos produtivos. O solo deve ser peça chave da fazenda e sua manutenção representa um diferencial que a fazenda estudada apresenta.

\section{Conclusão}

Apesar das dificuldades inerentes ao processo de estágio e acompanhamento enfrentados inicialmente, a realização do presente estudo pode ser vista como de extrema importância ao processo de aprendizagem e associação de teoria e prática.

$\mathrm{Na}$ propriedade estudada, as contribuições do estudo refletiram-se sobre aspectos diversos, levando o produtor a refletir sobre situações administrativas e sobre o processo de tomada de decisão. $\mathrm{Da}$ mesma forma, o produtor passou a buscar dar mais significado aos trabalhos de assistência técnica, que segundo ele mesmo servem de "choque tecnológico" para dar avanços aos trabalhos de campo.

Outro importante item constatado no estudo foi a natureza das estratégias do produtor no que se relaciona ao que produzir, quanto produzir e como produzir. Para ele, há necessidade de haver uma lógica nestas definições que podem representar o sucesso ou fracasso das atividades. Vale ressaltar que boa parte desta lógica é dependente de fatores internos, tais como solo, água, declive e outros fatores, inclusive dinheiro, mas, há também o fator mercado, que condiciona boa parte das decisões do proprietário.

Como principal contribuição, o estudo permitiu aos envolvidos (estagiário e proprietário) conhecerem um pouco mais dos problemas que estão ligados ã administração rural e suas variáveis mais importantes. Da mesma forma, muita das dificuldades identificadas serviram de motivação ao estudo.

Como sugestão de novos estudos é interessante que haja um maior conhecimento dos elementos econômicos das atividades produtivas da propriedade e os indicadores técnico-financeiros para melhor adequação dos recursos e esforços.

\section{Bibliografias}

Barbosa, J. S. Administração rural a nível de fazendeiro. São Paulo: Nobel, 1983. 90p.

Costa, P.J.A; Gonçalves, A.C.Fazendo um plano completo para o seu negócio. Disponível em http://www.milkpoint.com.br/plano.htm, acesso em 20 de junho de 2002.

Lacki, P. Rentabilidade na Agricultura: com mais subsídios ou com mais profissionalismo? Organização das Nações Unidas para a Agricultura e a Alimentação. Santiago, Chile. 1996. Disponível em http://www.milkpoint.com.br/fao/lacki.htm, acesso em 20 de junho de 2002.

Ludke, M., André, M.E.D.A. Pesquisa em educação: Abordagens Qualitativas. São Paulo: EPU,1986.

Megginson, L. C.; Mosley, D. C.; Pietri Jr, P. H. Administração: Conceitos e aplicações. Tradução Maria Isabel Hopp., São Paulo: Editora Harbra, 1998. 4 ed. 614p.

Mendonça, M.C. A.; Souza, T. P.; Reis, A. J.; Andrade, J.G. Admnistração rural e resultado econômico - um estudo de caso em Lavras-MG. In: Anais do I Congresso Brasileiro de Administração Rural, Lavras, 1995, ANAIS... Lavras: ABAR/UFLA, 1995. 167p.

Nantes, J. F. D.; Silva, A. L.; Batalha, M. O. Gerencia da propriedade rural - problemas e tendências. In: Anais do I Congresso Brasileiro de Administração Rural, Lavras, 1995, ANAIS... Lavras: ABAR/UFLA, 1995. $167 p$.

Reis, A.J.; Carvalho, F.A.P. Comercialização agrícola no contexto agroindustrial. Lavras: UFLA/FAEPE, 1999. 358p.

Souza, R.; Guimarães, J.M.P.; Vieira, G.; Morais, V. A.; Andrade, J.G. Administração da fazenda. São Paulo: Globo, 1992 211p. 